\title{
PESQUISAR ENTRE JOVENS E IMAGENS: A ESCOLA NO CAMINHO
}

\author{
Jaqueline Maria Conrad ${ }^{1}$ \\ Suzana Feldens Schwertner ${ }^{2}$
}

\begin{abstract}
RESUMO
O artigo busca discutir as peculiaridades da pesquisa com jovens, considerando-os como participantes ativos na investigação. A partir do encontro com estudantes concluintes do Ensino Médio de duas escolas do Vale do Taquari (RS), os jovens foram desafiados a produzir imagens que retratassem as funções da escola em suas vidas. As fotografias destacam o período escolar que estão finalizando, apresentando elementos que evidenciam normas e disciplinamento que ainda regem a escola. Também ressaltam a importância das relações interpessoais, por meio da amizade entre os jovens. Percebe-se o desejo e a motivação dos estudantes em participar da pesquisa, tendo suas vozes e olhares valorizados nesta investigação - tal como gostariam que acontecesse na escola.
\end{abstract}

Palavras-chave: Juventudes. Escola. Fotografia.

\section{RESEARCHING AMIDST YOUTHS AND IMAGES: THE SCHOOL IN THE WAY}

\begin{abstract}
This paper attempts to discuss the peculiarities of researching with youths by considering them as active participants. From meetings with students attending the last grade of High School in two schools in Vale do Taquari (RS), the youths were challenged to produce images portraying the functions of the school. The photographs highlight the final school period they are experiencing, and present some elements to evidence the norms and discipline that still rule the school. The participants also emphasized the importance of interpersonal relationships by means of friendship. It is possible to notice the students' desire and motivation to take part in the research having both their voice and view valued in this investigation, as they wish they would at school.
\end{abstract}

Keywords: Youth. School. Photography.

O presente trabalho é proposto a partir do projeto de pesquisa "A escola e as novas configurações da contemporaneidade: a voz de estudantes concluintes do Ensino Médio e Fundamental" (MCTI/CNPQ/Universal 14/2014), vinculado ao

\footnotetext{
${ }_{1}^{1}$ Psicóloga. Foi bolsista de Iniciação Científica entre 2015 e 2017 na Universidade do Vale do Taquari. 2 Psicóloga. Doutora em Educação. Docente do PPGEnsino da Univates e do curso de Psicologia na mesma instituição. Foi coordenadora do projeto de pesquisa que é apresentado no artigo.
} 
Mestrado em Ensino da Universidade do Vale do Taquari - Univates. A pesquisa teve como objetivo discutir as configurações da escola na atualidade, por meio da investigação com jovens estudantes concluintes do último ano do Ensino Fundamental e Médio, entendendo os estudantes como participantes ativos de seus processos de ensino e de aprendizagem.

A pesquisa utiliza como aporte teórico autores como Michel Foucault (2015; 2002), Júlio Groppa Aquino (2000), Jorge Larrosa (2000; 2004), Paula Sibilia (2012), Jan Masschlein e Maarten Simons (2014). Nas discussões sobre juventudes, baseiase nos estudos de Dayrell (2003, 2007), Schwertner e Fischer (2012) e Schwertner (2012).

Tal investigação é qualitativa, por meio da técnica de grupo focal (GATTI, 2005), integrando também um trabalho de discussão coletiva com os estudantes, por meio de foto elicitação de Marcus Banks (2009; 2001). Neste processo, os estudantes são instigados a pensar sobre os sentidos da escola e convidados a produzir uma fotografia sobre as funções da instituição escolar na atualidade. Esta investigação teve início no ano de 2015 e finalizou no início de 2018, sendo a pesquisa de campo realizada nos meses de maio e junho de 2015, 2016 e 2017. Participaram, no total, 117 estudantes de duas escolas de Lajeado (RS), uma de ensino público e outra de ensino privado.

Foram realizados quatro encontros com os alunos concluintes do $9^{\circ}$ ano do Ensino Fundamental e do $3^{0}$ ano do Ensino Médio. Cada encontro, em formato de grupo focal, possuía uma temática previamente selecionada: no primeiro momento, perguntávamos para os estudantes quais as funções da escola hoje?; no segundo encontro, como a escola organiza a divisão dos saberes/conhecimentos?; no terceiro, foram retomadas as discussões iniciais e a partir delas foi proposto que se produzisse uma fotografia, seguida de uma legenda, que apresentasse os sentidos da escola para os estudantes. No quarto e último encontro, tais fotografias foram compiladas em um arquivo único e os estudantes assistiram coletivamente a todas as imagens, discutindo sobre suas produções.

O presente artigo busca analisar as peculiaridades da pesquisa com jovens e não apenas sobre eles -, considerando-os como participantes ativos no processo de investigação. A partir disso, tem como objetivo específico analisar as fotografias 
produzidas pelos estudantes do $3^{\circ}$ ano do Ensino Médio, participantes da pesquisa no ano de 2016, explorando a forma como a escola constitui esses sujeitos e igualmente produz sentidos a eles.

Em seguida, no texto, discutiremos sobre as juventudes, buscando no estudo do referencial teórico quem são os jovens estudantes de hoje no cenário brasileiro, conforme pesquisadores da temática. Após a discussão, seguiremos através da trilha metodológica desta pesquisa, apresentando os resultados e discussões propostas.

\section{PESQUISANDO ENTRE JOVENS}

É exatamente a proposta do teu projeto que é extremamente falha aqui na escola, sabe? E se a escola, se a base da escola é a gente, se quem constroi a escola é a gente, então para melhorar a escola, então deveria ser ouvido o que a gente diz. Sabe, a proposta do teu projeto é exatamente o que a gente tenta (Estudante de $3^{\circ}$ ano do Ensino Médio, participante da pesquisa em 2015).

Juventudes e escolarização, jovens e escola. Mas, afinal, quem são estes jovens que estão na escola? Como caracterizamos as juventudes na escola? Que espaço proporcionamos para suas manifestações, para suas denúncias, para seus clamores? E para que possam conversar sobre a escola, esta instituição a qual pertencem, mas que poucas vezes são chamados a opinar e a falar sobre ela?

A frase que abre esta subseção do artigo é proposta por uma estudante concluinte do Ensino Médio participante do projeto de pesquisa no ano de 2015, durante o último encontro com o grupo. A estudante apresenta uma espécie de denúncia do lugar ocupado pelos jovens na escola, de alguém a quem não é permitida a fala, que não é capaz de contribuir para a escola: se a escola é direcionada aos alunos, pensando em melhorias para os mesmos em seus processos de ensino e de aprendizagem, por que os jovens não são ouvidos nesse espaço? Mas, antes de adentrar o universo escolar e pensar os jovens que ali estão in/excluídos, passamos a discutir sobre as juventudes na contemporaneidade.

Segundo Dayrell (2003), é difícil encontrar um conceito único para caracterizar a juventude, já que ela é constituída por critérios históricos e culturais. As mudanças físicas e psicológicas vão acontecer de modo diferente em cada grupo social:

Essa diversidade se concretiza com base nas condições sociais (classes sociais), culturais (etnias, identidades religiosas, valores) e de gênero, e 
também das regiões geográficas, dentre outros aspectos (DAYRELL, 2003, p.46).

Por isso, torna-se impossível determinar apenas juventude, no singular: é preciso que pensemos sobre juventudes no plural.

De acordo com Schwertner e Fischer (2012), o termo "juventude" começou a ser utilizado por volta dos anos 50 do século $X X$ e a partir de então foi sendo modificado, ampliado, relacionado a determinados personagens e comportamentos característicos. Segundo as autoras, tal fase:

[...] oscila entre vários registros: de uma simples fase da vida, muitas vezes associada às noções de vitalidade, otimismo e descoberta, a uma força social renovadora (em certas situações e épocas tornando-se sinônimo de rebeldia e até de delinquência - classicamente visível na figura do ator James Dean e de seus personagens no cinema): ou, para além de uma etapa cronológica, de um tempo de quase irresponsabilidade e dependência, ao momento de constituição de um modo de existência próprio (SCHWERTNER; FISCHER, 2012, p. 397).

Dayrell (2003) em uma das suas pesquisas sobre diferentes juventudes na contemporaneidade, buscou um outro olhar para esses jovens ligados aos grupos musicais de rap e funk, compreendendo-os como sujeitos sociais. Por meio de tal estudo, o autor apresenta três imagens que estão presentes em nossa sociedade e caracterizam a juventude contemporânea: transitoriedade, romantização e crises.

A primeira imagem apresentada por Dayrell (2003) é a transitoriedade, que problematiza o jovem como um "vir a ser", como aquele que importa apenas pelas suas ações do presente visando o futuro. De acordo com o autor, uma das visões: "[...] mais arraigadas é a juventude vista na sua condição de transitoriedade, na qual o jovem é um "vir a ser", tendo no futuro, na passagem para a vida adulta, o sentido das suas ações no presente" (DAYRELL, 2003, p. 40). Os alunos são vistos pela família, pela escola e pela sociedade como pessoas que ainda estão buscando seu lugar e muitas vezes sem nem terem o direito de opinar sobre os assuntos aos quais estão diretamente ligados - inclusive, no espaço da escola, lugar em que permanecem, obrigatoriamente, durante cinco dias da semana, por minimamente quatro ou até oito horas ao dia.

Tal afirmação é apresentada também por Schwertner e Fischer (2012) que apontam e criticam a forma como os jovens ainda são vistos pela sociedade:

O senso comum parece insistir numa discursividade que associa o jovem a alguém muitas vezes perdido em um corredor escuro, para o qual só resta a 
"luz" do mundo adulto - lugar do equilíbrio e da autonomia, muito distante daqueles tempos e lugares incertos e tortuosos por ele vividos (SCHWERTNER; FISCHER, 2012, p. 396).

A segunda imagem apresentada por Dayrell (2003) versa sobre uma visão romântica da juventude que, segundo o autor, instaurou-se por volta de 1960: resultante do crescimento da indústria cultural e um mercado consumidor dirigido ao público jovem. A partir dessa perspectiva, "[...] a juventude seria um tempo de liberdade, de prazer, de expressão de comportamentos exóticos" (DAYRELL, 2003, p. 41), compreendendo a fase como um ensaio de erros e acertos, além da irresponsabilidade.

O alargamento da juventude também tem sido alvo de discussões. Como destacado por Schwertner e Fischer (2012), tal ampliação não implica obrigatoriamente em um outro olhar para os jovens. Essas discussões têm apresentado uma diminuição do período denominado como infância e antecipado a entrada ao mundo adulto, inclusive com as criações de novas categorias, tais como: pré-adolescente e adulto jovem.

Outra imagem que convive com a caracterização da juventude, de acordo com Dayrell (2003), é a fase das crises, baixa auto-estima, conflitos de personalidade, maior afastamento da família. Para o autor, é importante questionar tais imagens difundidas pela sociedade, para não corrermos o risco de olhar para a juventude de forma negativa; para isso, ele se detém a pesquisar os múltiplos atravessamentos na vida jovem.

Tais visões, como as que foram acima apresentadas, levantam sobre a juventude contemporânea apenas olhares críticos, negativos, que negam as potencialidades dos jovens e das investigações que envolvem esse sujeitos como participantes ativos. Assim, busca-se olhar para a juventude como uma fase que "já é", que considera os jovens naquilo que eles vivem e não apenas no que irão se tornar, compreendendo as responsabilidades e questões nas quais estão envolvidos. Como ser jovem em uma sociedade onde, além dos conflitos internos que estão vivenciando, precisam lidar com as visões negativas sobre eles? Como as escolas têm se preparado para receber e atender essas juventudes?

Leão, Dayrell e Reis (2011) posicionam-se criticamente sobre a culpabilidade que é colocada sobre os jovens, como se eles fossem os responsáveis pelo fracasso 
da instituição escolar na atualidade. Com isso, os autores criticam o despreparo da escola para atender as juventudes que circulam nesse espaço, em que ser aluno aparece como um processo natural:

Independentemente do sexo, da idade, da origem social ou das experiências sociais vividas, é a sua condição de aluno, quase sempre na sua dimensão cognitiva, que irá informar a compreensão que o professor ou o pesquisador constrói desses atores (LEÃO; DAYRELL; REIS, 2011, p. 1068).

Sendo que, ainda em outros tempos, há 30 ou 40 anos, quando o jovem entrava na escola, pensava-se que ele deixava do lado de fora do portão a sua realidade, para dentro assumir a identidade de aluno (com todos os rigores, normas e disciplina exigidos). Da mesma forma, os alunos não eram considerados com as suas questões, aspectos, peculiaridades da juventude. Importantes mudanças socioculturais têm ocorrido e a escola "tem sido invadida pela vida juvenil" (DAYRELL, 2007, p. 1120) por meio de uma série de elementos:

[...] com seus looks, pelas grifes, pelo comércio de artigos juvenis, constituindo-se como um espaço também para os amores, as amizades, gostos e distinções de todo tipo. O "tornar-se aluno" já não significa tanto a submissão a modelos prévios, ao contrário, consiste em construir sua experiência como tal e atribuir um sentido a este trabalho (DAYRELL, 2007, p. 1120).

Discutir sobre a escola na contemporaneidade e sobre os jovens que ali estão passa por questionar as origens desta instituição. Os autores Masschelein e Simons (2014, p. 37) questionam a forma com que muitas vezes a escola é apresentada, sendo indicada como um "local de passagem ou de transição". Para os autores, a instituição escolar precisa ser pensada como um espaço onde se vive o presente, onde se experimenta para o momento:

\footnotetext{
Nesse sentido, o espaço escolar é aberto e não fixo. O espaço escolar não se refere a um local de passagem ou transição (do passado ao presente), nem a um espaço de iniciação ou de socialização (da família para sociedade). Pelo contrário, devemos ver a escola como uma espécie de puro meio ou centro. A escola é um meio sem um fim e um veículo sem um destino determinado (MASSCHELEIN; SIMONS, 2014, p. 37).
}

Foi partindo deste entendimento de escola que propomos a seguinte investigação. Tal pesquisa tem como propósito lançar um olhar para a escola por meio das imagens produzidas por estudantes do $3^{\circ}$ do Ensino Médio, tomando a escola e os jovens estudantes - como centralidade. 


\section{METODOLOGIA}

Como buscar compreender e identificar as peculiaridades da pesquisa com jovens? Como os jovens estudantes apresentam a importância e os sentidos da escola em suas vidas por meio da produção de fotografias? São essas algumas questões que norteiam tal estudo, do qual participaram vinte e três estudantes concluintes do $3^{\circ}$ ano do Ensino Médio, de duas escolas do interior do Rio Grande do Sul. Em cada uma das instituições, foram desenvolvidos quatro encontros, com a duração de 45 minutos cada.

Os estudantes participaram da investigação voluntariamente, após um convite realizado às turmas. Destes, foram selecionados de oito a doze estudantes, buscando, conforme Gatti (2005), facilitar as discussões e debates realizados nos encontros. Foram utilizados o critério de iniciativa e ordem de inscrição para a seleção dos participantes. Além disso, para participar da investigação, os estudantes precisaram apresentar o Termo de Consentimento Livre e Esclarecido (TCLE) assinado pelos pais ou responsáveis, bem como um Termo de Assentimento, elaborado especialmente para a autorização dos próprios jovens. Os encontros, após acordado com os participantes, foram gravados por meio de um gravador digital e posteriormente transcritos na íntegra.

Destacamos, neste escrito, as discussões envolvendo o terceiro e quarto encontro com o grupo de jovens selecionados, de um total de quatro encontros propostos na investigação: no terceiro, os estudantes foram desafiados a produzir uma fotografia seguida de legenda que demonstrasse os sentidos da escola em suas vidas. E no quarto, as fotografias foram compiladas em um arquivo e contempladas coletivamente pelos estudantes. No momento em que os estudantes assistiam às fotografias, os mesmos as discutiam por meio da técnica de foto elicitação. Conforme Schwertner e Conrad (2016), tal método de pesquisa tem sido utilizado como promotor de debates e possibilitado a ampliação do olhar dos jovens estudantes:

[...] permite a discussão coletiva dos materiais produzidos pelos próprios participantes (no caso, as fotografias), colocando-os como responsáveis pelos dados que estão sendo produzidos. Além da produção da imagem, os estudantes assistem a todas fotografias em conjunto e debatem sobre as mesmas: o que chamou a atenção deles, ângulos, paisagens, detalhes e, ainda, questionam os colegas sobre o que pensaram na hora de fotografar a escola (SCHWERTNER; CONRAD, 2016, p. 34). 
A técnica de investigação é proposta por Marcus Banks (2009), que apresenta duas correntes presentes nas pesquisas que se utilizam das metodologias visuais: a primeira delas é quando a criação de imagens é feita pelo próprio pesquisador, que produz a fotografia para documentar e analisar aspectos das interações e histórias pessoais dos sujeitos. Nesse processo, a discussão dos participantes ocorre independentemente de eles conhecerem as fotografias, compreenderem ou se interessarem por elas. A segunda corrente corresponde àquela em que as imagens são produzidas pelos próprios sujeitos de pesquisa, ou seja, a discussão parte das fotografias que os estudantes pensaram, elaboraram e produziram. Conforme Banks (2009, p. 21): "Aqui o foco do projeto de pesquisa é mais obviamente visual, e os sujeitos de pesquisa têm, de forma mais evidente, uma conexão social e pessoal com as imagens" (BANKS, 2009, p. 21). Na presente investigação, optamos por este segundo modo de pesquisar, levando em consideração o olhar dos jovens estudantes para a escola na contemporaneidade.

Um dos benefícios destacados por Banks (2008) na utilização dessa metodologia, em que os participantes criam e produzem as próprias fotografias (que são então utilizadas na discussão posterior), é de tornar a participação do sujeito mais espontânea, além de colocá-los como participantes ativos e responsáveis na investigação. Possibilitar discutir acerca de suas próprias produções também proporciona um reconhecimento daquilo que conta sobre suas vivências, seu entorno, sua história de vida.

Na sequência, apresentamos os resultados da pesquisa, por meio da análise das fotografias e do debate coletivo produzidos pelos jovens estudantes. A análise do material aproximou-se da análise discursiva proposta por Michel Foucault (2002), entendendo que os discursos não estão localizados na voz dos estudantes, mas perpassam movimentos e processos do contexto histórico e social, atravessando os jovens e os produzindo como sujeitos sociais de uma dada cultura e tempo histórico. Importa ressaltar aqui, especificamente, as condições de emergência de um discurso que aborda aspectos de um tempo e espaço específico: aquele que aponta para a conclusão do processo de escolarização - a saída da escola, finalizando os estudos 
no Ensino Médio - e sua configuração para um grupo de estudantes, apontando para os dilemas, os desafios e as perspectivas com sua trajetória após a escola.

\section{RESULTADOS}

Como discutido na introdução deste artigo, por essa investigação contar com a participação ativa dos estudantes, não nos interessa pesquisar sobre jovens, mas sim com os jovens e nessa pesquisa conjunta, nos deparamos com uma série de peculiaridades que se atravessam em meio à investigação com esse público específico e com a produção de imagens.

Pesquisar com jovens apresenta uma diversidade de desafios aos investigadores: a espontaneidade, a participação, a intensidade das trocas e os múltiplos atravessamentos - de interesses, de assuntos, de opiniões, de críticas compõem diferentes modos de se produzir um trabalho de investigação. O interesse, a motivação e a participação dos jovens estudantes foram percebidos como fundamentais ao trabalho de pesquisa. Quando são incentivados a participar ativamente, utilizam-se desse momento para pensar, fazer sugestões e até mesmo críticas sobre o espaço que estão inseridos e - por que não? - a eles mesmos.

Os jovens destacaram, nesta investigação, o fato de terem um momento de reflexão e discussão sobre a escola e, até mesmo, para repensar seu papel de estudantes nesse espaço. Entendemos que os jovens têm o desejo de falar, questionar e pensar sobre a escola, sobre os processos de ensino e de aprendizagem e que também gostariam que suas vozes fossem ouvidas por todos aqueles que compõem esse cenário. Solicitam que a escola deveria promover mais espaços que possibilitem o diálogo, a discussão e a troca de ideias.

Quando desafiados a produzir uma fotografia que retrate o sentido da escola em suas vidas, os jovens estudantes destacaram, além das funções da escola (pedagógica, política, social), os efeitos que a escola tem exercido sobre os estudantes em formação. Destacou-se fotografias que apresentaram: saída da escola - período de conclusão de uma etapa da vida, considerando o fato de tratarem-se de estudantes concluintes do Ensino Médio; tempo, normas e disciplinas na escola que aparecem através de elementos como o relógio, o quadro, os materiais escolares; e a 
valorização das relações interpessoais, destacada nas fotografias que demonstram a amizade entre os estudantes.

A seguir destacamos seis imagens produzidas pelos jovens estudantes do $3^{\circ}$ ano do Ensino Médio, em que buscamos realizar uma conversa entre as fotografias e os discursos dos estudantes. Utilizamos da letra "E" para identificar os estudantes, "P" para pesquisador, e os numerais: “1”, "2", "3" para diferenciar os jovens. Como por exemplo E1, E2, E3...

Imagem 1 - Subindo os degraus do conhecimento

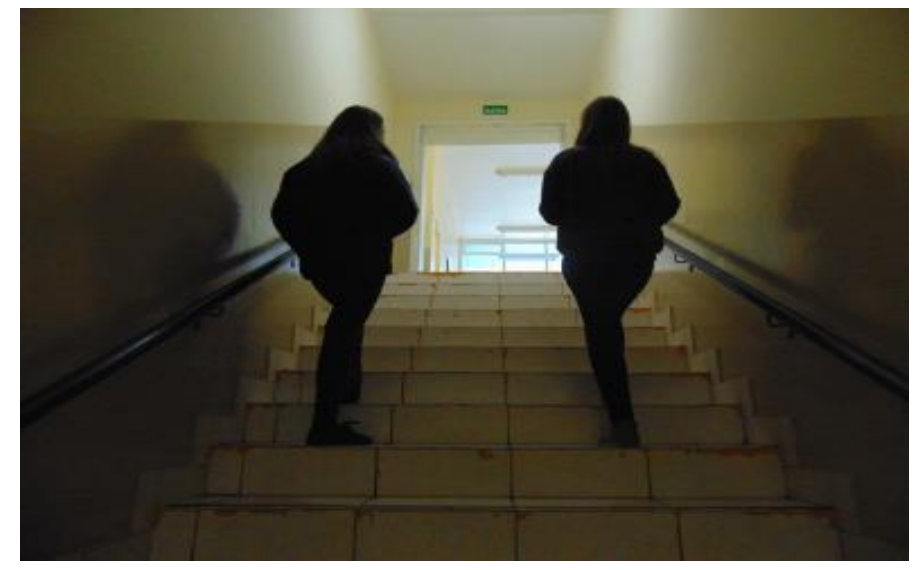

Fonte: Estudante 10

$\mathrm{Na}$ Imagem 1, intitulada pela estudante E10: "Subindo os degraus do conhecimento", é possível observar uma escada de azulejos e duas estudantes que se posicionam de costas para quem fotografa: elas estão no movimento de subida dessa escada. Podemos perceber as sombras de cada uma das estudantes refletidas nas paredes beges e amarelas da escola. Mais acima da imagem podemos visualizar uma porta ao fundo, com uma placa verde indicando a "Saída"; por essa saída, entra uma luz que transmite claridade para o ambiente, quanto mais distante da porta de saída, mais escura a imagem se torna.

Ao "subirem os degraus do conhecimento", os estudantes apontam para o fato de se desenvolverem na escola e de que até o momento passaram praticamente toda a vida deles dentro da instituição escolar, refletindo sobre o crescimento, a formação tanto intelectual quanto social que tiveram nesse espaço. Reflexão que é também possível, por causa da etapa da vida eles estão vivenciando: conclusão do Ensino 
Médio, como podemos observar nas falas das estudantes que comentam sobre a imagem:

E2 - São várias etapas que tu vai passar na escola e tudo mais.

E2 - Então pensei nas diversas formas de ver as coisas que a gente aprende ou acaba aprendendo, ou acaba mostrando jeito de agir ou acaba se descobrindo, na escola tu se descobre novos horizontes. (Pausa).

E10 - Cada degrau que tu está subindo é um desafio que tu conseguiu superar, aí no final, no caso o terceiro ano, tu vai encontrar a saída. (Dados do registro de campo, 30/06/2016)

Torna-se interessante observar a escuridão dessa escada e o ponto de luz acima, o que nos faz lembrar da transitoriedade apresentada por Dayrell (2003) e a escuridão que perpassa a juventude citada por Schwertner e Fischer (2012). Além de ser uma visão que desvaloriza a juventude, percebemos que os jovens também têm se colocado nesse lugar de "corredor escuro", de transitoriedade, de um "vir a ser" que ainda não é possível neste momento da vida - mais adiante, quem sabe, após a passagem pela "saída". Saída a qual é apresentada novamente na fotografia a seguir, produzida pela estudante 9:

\section{Imagem 2 - Novo começo}

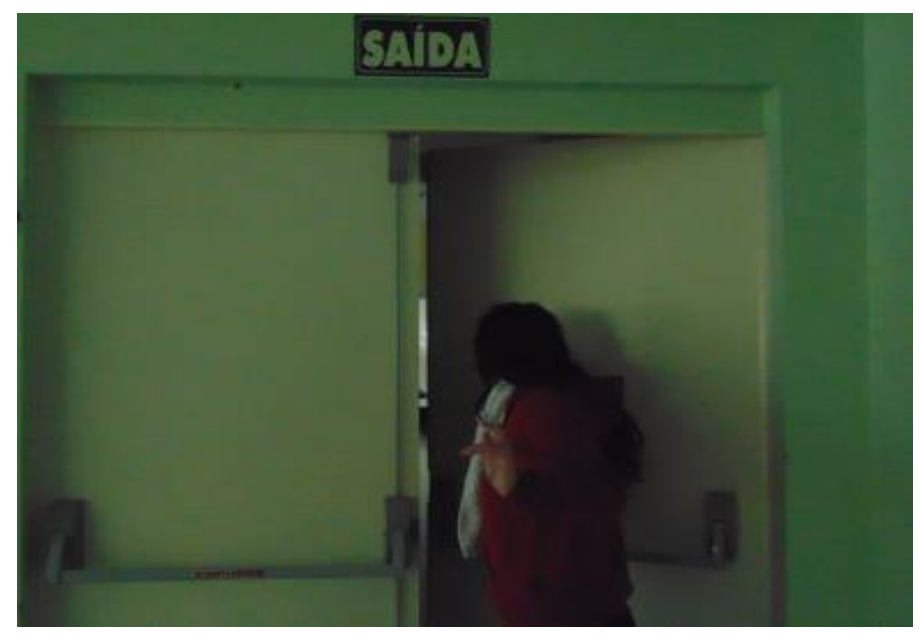

Fonte: Estudante 9

A imagem 2 tem como elemento em destaque uma porta, que aparenta estar sendo aberta pela pessoa que se coloca de lado para ela. A porta tem a opção de abrir seus dois lados, mas apenas um está entreaberto, além disso, barras nas portas. A pessoa está com o corpo em direção oposta a cabeça: a cabeça está em direção ao outro lado da porta, talvez espiando o que tem por trás, será um "novo começo"? 
Acima da porta, é possível visualizarmos uma placa verde em que lemos: saída. $\mathrm{Na}$ discussão que se seguiu sobre a fotografia, as estudantes revelaram a intencionalidade na produção dessa imagem: em que buscaram um lugar escuro para fotografarem. Como podemos perceber a seguir:

\begin{abstract}
E9 - A imagem está escura e tem uma guria abrindo a porta: eu. Significa, tipo assim... uma coisa que tu não espera, tu não sabe o que tem ali atrás, é escuro porque o novo é escuro, tu precisa entrar nele e olhar para dentro dele para ti entender o que é novo, as novas oportunidades, é isso que a gente quis mostrar. E... realmente, a gente procurou um lugar escuro para tirar a foto. Talvez não seja bom para ver agora, mas tipo... foi para não dar para ver o que tem ali.
\end{abstract}

E1 - Eu acho que a escola seria um jeito de te dar mais certeza, de te dizer, de te colocar pressão para ver realmente se é isso e tu tem certeza de que é isso que tu quer, se é assim que tu quer teu futuro. (Dados do registro de campo, 30/06/2016)

Nesta fotografia e discussão, os estudantes retratam novamente o período de saída da escola: de conclusão de uma etapa da vida. A saída da escola aqui é sinalizada como um "novo começo" pela E9 que produziu a imagem, como se atrás dessa porta (na saída da escola) os estudantes pudessem encontrar esse lugar que almejam: de segurança, de direitos sobre si, de escolhas. Ainda relacionando aqui com a transitoriedade, nessa fotografia é a porta que marca essa transição, a saída de um lugar escuro, simbolizando um novo começo. De acordo com Dayrell (2003):

Essa concepção está muito presente na escola: em nome do "vir a ser" do aluno, traduzido no diploma e nos possíveis projetos de futuro, tende-se a negar o presente vivido do jovem como espaço válido de formação, assim como as questões existenciais que eles expõem, bem mais amplas do que apenas o futuro (DAYRELL, 2003, p. 41).

As próximas duas fotografias marcam o tempo na escola, a obrigatoriedade de conhecer e estudar todos os conteúdos até as provas de classificação, como o Exame Nacional do Ensino Médio (ENEM) e os vestibulares. Regidos pelo relógio, que comanda a cena nas fotografias, os jovens estudantes marcam a trajetória de sua passagem pela escola, seja o relógio apontando para um tempo que não retorna mais, de conteúdos e inícios e finais de períodos bem demarcados, seja apontando para a disciplina e os "nãos" que ela implica. Uma escola que é marcada pelo relógio: hora disso, hora daquilo... 
Imagem 3 - Mesmo correndo o conteúdo nunca se atrasa

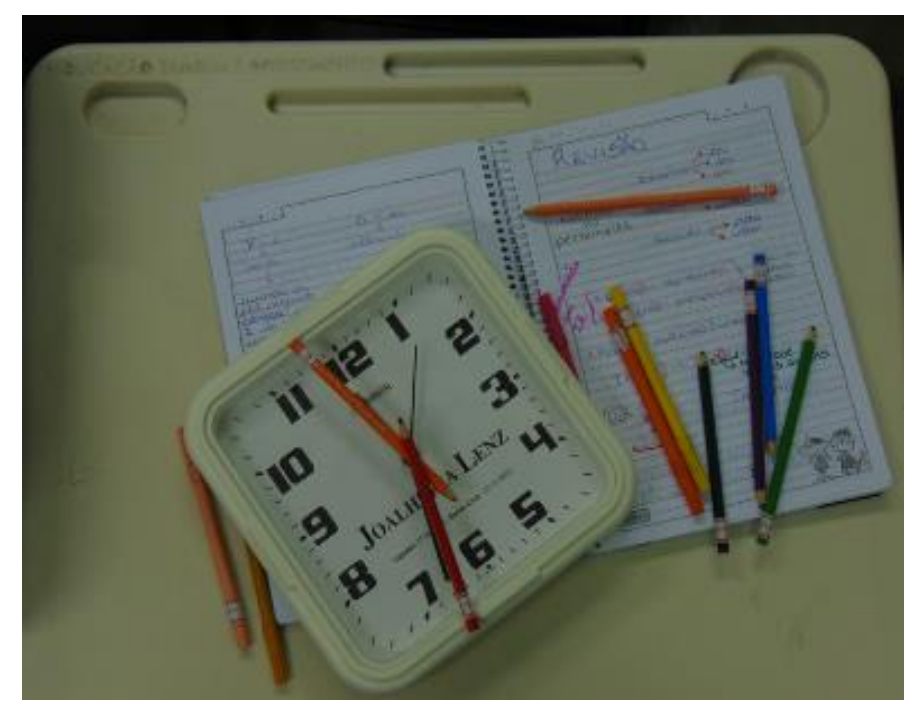

Fonte: Estudante 13

Na fotografia (Imagem 3), intitulada pela E13: "Mesmo correndo o conteúdo nunca se atrasa", ela destacou uma carteira (mesa) escolar, sobre a mesa, encontrase um caderno aberto e no lado direito superior do mesmo lemos a palavra "revisão". Ainda em cima do caderno e da mesa, lápis e canetas hidrocor coloridas são espalhadas de forma aleatória. Tais lápis e canetas hidrográficas possuem em sua base superior etiquetas, utilizadas pela estudante para identificar seus materiais escolares.

Sobre o lado esquerdo do caderno, um relógio de parede branco com numerais pretos ocupa boa parte da página (e da fotografia). Sobre os ponteiros que marcam as horas e os minutos, a estudante escolheu lápis nas cores laranja e vermelho para representar os ponteiros. Relógio que marca o tempo, tempo que rege um conteúdo que "corre", mas que "nunca se atrasa": a demarcação do tempo, sua delimitação, controle, vigilância apontam para ações cotidianas da escola (FOUCAULT, 1997), que é regida pelo "tic-tac" dos relógios. Analógicos, estão presentes em todas as salas de aula e ocupam um lugar de destaque: tal como Lopes e Veiga-Neto (2004) destacaram, torna-se um elemento indispensável para a Modernidade e, em sua esteira, a instituição escolar.

Ainda, no canto superior esquerdo da foto, na superfície da classe, é possível ler uma inscrição que anuncia: “Educação também é investimento". De que 
investimento estamos falando aqui? O investimento em materiais, em disciplinas, no tempo que escoa? Como pensar em um investimento que "não corra e nem se atrase", que respeite o tempo de cada envolvido no processo da educação?

$\mathrm{Na}$ discussão que sucedeu à exibição da fotografia, os estudantes destacaram a obrigatoriedade em 'dar conta' de todos os conteúdos, questão que para eles mostra-se mais evidente no 3ํano do Ensino Médio:

E1 - É que eu vejo muito isso agora, sabe? Isso eu acho que me deixa muito irritada, porque a gente não consegue às vezes, pegar bem o conteúdo, é o que está acontecendo principalmente agora no terceiro ano. Mas estão correndo muito com o conteúdo, conteúdo vai, vai, só vai porque não pode se atrasar, não pode... Tem que ter aquilo no final do ano. E tipo assim... por mais que tu não pegue, o importante é dizer que foi passado.

E13 - Tu tem que arrumar algum jeito, sabe? Se tu não aprendeu, vida que segue.

(Risos do grupo).

E13 - Tu vai ter... eu aprendi todo conteúdo de uma matéria antes da trimestral. Eu não aprendi porcaria nenhuma na aula. Tipo, vida que segue, né? Eu tive que aprender.

E16 - E eles são obrigados a passar aquilo, então mesmo que o aluno não aprendeu, elas não vão ficar demorando no conteúdo, conteúdo vai atrasar. Então, elas passam e continuam, porque elas têm obrigação de passar todo conteúdo. Então... elas não estão muito preocupadas se tu entendeu tudo, eu acho. (Dados do registro de campo, 30/06/2016)

Imagem 4 - Nem o tempo, nem as regras, nenhum é relativo

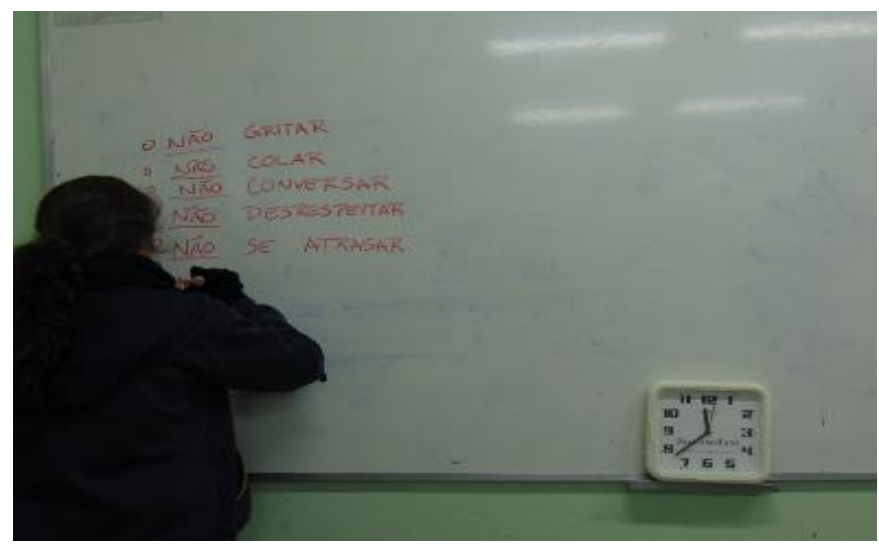

Fonte: Estudante 1

$\mathrm{Na}$ imagem 4, a estudante "E1" aparece como personagem na cena: coloca-se de costas para quem fotografa, a imagem apresenta apenas uma parte do corpo, mas 
percebe-se na cena que ela está escrevendo algo no quadro com a mão direita. Um quadro escolar na cor branca com as bordas pratas preenche praticamente toda imagem, nele a estudante escreve tópicos com uma caneta vermelha, nos quais sublinha a palavra "não": "Não gritar", "Não colar", "Não conversar", "Não desrespeitar", "Não se atrasar". No lado direito da imagem, sob o lugar destinado para o apagador, a estudante colocou o relógio de parede (o mesmo presente na fotografia anterior) da sala de aula.

A respeito dessa imagem apresentou-se a seguinte colocação:

E1 - Eu pensei essa legenda quando vi a foto pelo fato de que a escola tem regras e... tem de novo essa questão do tempo, que temos que correr contra o tempo. Nenhum dos dois vão ser relativos, como diria Einstein, que o tempo seria relativo, nenhum dos dois na escola vai ser relativo, porque tem um prazo determinado. Então não tem: ah, vamos prorrogar um pouquinho mais o conteúdo, porque ele é mais legal, dá para se divertir mais. Não! É aquele tempo, aquele tempo determinado, porque existe essa regra e essa regra também não é relativa, também não tem uma exceção. Então, tem que ser assim porque tem metas para cumprir no final ano... no final de cada ano. $\mathrm{E}$ cada escola tem que ter certa média no ENEM para ter uma escola de qualidade. Então... nada pode ser relativo, porque as medidas elas têm que ser certas para te dizer o que é bom e o que é ruim. (Dados do registro de campo, 30/06/2016)

Percebe-se pela fotografia e no excerto apresentado que seguiu na discussão do encontro, o quanto a disciplina, a normatização e os rigores ainda estão presentes dentro das salas de aulas na atualidade. Assim como afirma Sibilia (2012), que mesmo com todas as transformações que a escola passou desde a sua criação, ainda se encontra com os tradicionais modos de funcionamento: a exigência pelo rigor, pela disciplina, com ênfase na normatização. De acordo com a autora:

Tais rigores alimentam as engrenagens oxigenadas dessa instituição de confinamento fundada há vários séculos e que, mais ou menos fiel a suas tradições, continua a funcionar com o instrumental analógico do giz e do quadro-negro, dos regulamentos e boletins, dos horários fixos e das carteiras alinhadas, dos uniformes, da prova escrita e da lição oral (SIBILIA, 2012, p. $51)$.

Sobre os "nãos" enfatizados na imagem, a estudante também comentou:

E5 - Tipo assim... a gente colocou um monte de nãos porque é o que mais a gente ouve desde pequeno é "não, não pode fazer isso", "não, não pode gritar", "não pode comer enquanto está na aula". Nunca é um "pode, pode comer no recreio". É sempre o "não comer na aula", nunca alguma coisa positiva. Sempre dando ênfase no que não se pode fazer. (Dados do registro de campo, 30/06/2016) 
As normas, regras, disciplinamentos, características do movimento que rege a instituição escolar são nesta discussão representadas pelos estudantes por meio da negativa: o uso do "não" aparece em suas falas e na palavra grafada em cor vermelha, no quadro da sala de aula. Na discussão, os estudantes sugerem possibilidades de que as regras sigam existindo, mas que elas possam ser expressas de modos diferenciados, por meio de uma ação afirmativa, por exemplo.

As últimas duas fotografias apresentam o papel social da escola, defendido com intensidade entre os estudantes, a valorização das relações interpessoais que construíram ao longo dos anos escolares, que para eles se tornou uma marca da escola.

Imagem 5 - Todos abraçados, momentos que passamos juntos vai ficar para sempre

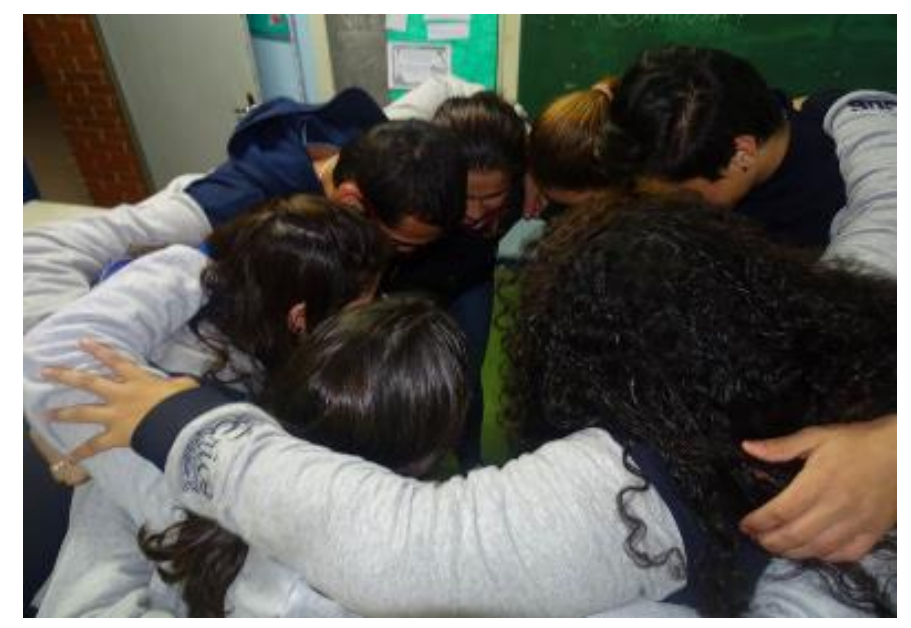

Fonte: Estudante 5

Na imagem: "Todos abraçados, momentos que passamos juntos vai ficar para sempre" (Imagem 5), o fotógrafo posiciona-se com a câmera em cima do círculo, composto por sete estudantes do terceiro ano que, com os braços em cima dos ombros um dos outros e com as cabeças em direção ao chão (quase encostando uma na outra), formam um círculo. Em segundo plano, percebemos a porta da sala aberta, como um convite para quem quiser entrar e fazer parte do grupo. Além da porta, enxergamos uma parte do mural da sala com algumas folhas expostas e ao lado, o quadro verde que na parte superior aparece o pedaço de uma palavra escrita, não sendo possível identificá-la na imagem. 
Ao assistirem coletivamente essa fotografia, os estudantes destacaram a relevância do papel social da escola, afirmando que em que muitas vezes convivem mais tempo com os colegas do que com a própria família. Referem-se também ser esses os "amigos de verdade" que levarão para a vida. Como é possível perceber nos excertos a seguir que partiram das discussões dessa fotografia pelos estudantes da escola Y:

E5: [...] a gente vive em família durante um ano, vivemos uma panelinha, e até o final do ano todos dentro da sala estarão sentados um perto do outro, aqui temos amigos e tudo mais, passamos muitas vezes mais tempos com eles do que com nossa família, tem gente que levamos para vida inteira como se fosse irmãos.

E3: Amigos de verdade a gente leva para vida toda, e na escola tu vê quem são teus amigos de verdade e quem são colegas. (Dados do registro de campo, 23/06/2016)

Amizade que compartilha as angústias do estar na escola, de seguir e incentivar a continuidade dos estudos, amigos que ajudam a "resolver os problemas", como destacado por Schwertner (2012):

Apesar da força de um discurso da amizade que ainda insiste em utilizar a metáfora familiar, em apelar para a semelhança e a harmonia entre os amigos, podemos perceber que as diferenças também contam para as relações de amizade - e, em alguns momentos, de maneira bem marcada pelos jovens. Os estudantes passam então a nomear as brigas, a falta de consenso e trazer as diferenças de opinião, de gosto, de comportamento, de pensamento, como componentes também importantes dos laços de amizade que a escola proporciona (SCHWERTNER, 2012, p. 179).

Na fotografia a seguir, os estudantes seguiram a discussão sobre as relações interpessoais, principalmente aquelas consideradas "amizades concretas":

Imagem 6 - Amizades concretas

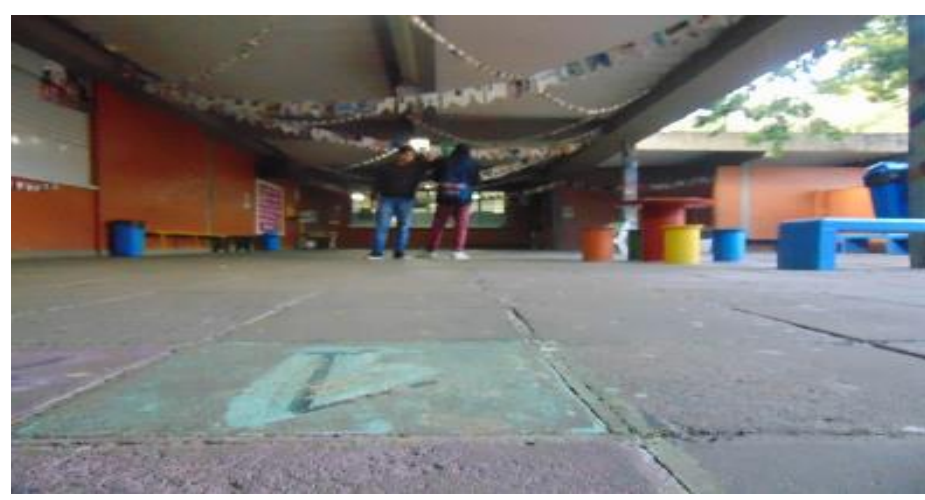

Fonte: Estudante 2 
$\mathrm{Na}$ "imagem 6" o estudante produziu a foto na área coberta da escola, um local de lazer: com mesas e bancos coloridos; algumas marcas apagadas do que já foi um "jogo de amarelinha". A foto nos passa a impressão de que a câmera tenha sido posicionada no chão para produzir a fotografia, a imagem aparece também desfocada. No centro da cena, dois estudantes aparecem em foco, um dos meninos aparece de frente para a câmera e o outro de costas, ambos se encontram pelos braços entrelaçados, como uma brincadeira pelos estudantes. Acima dos estudantes, bandeirinhas preenchem a cena, decoração típica das festas de inverno nas escolas.

Sobre essa imagem, os estudantes destacaram a importância das amizades em suas vidas e de que em algumas situações, são essas amizades que fazem com que os estudantes não desistam dos estudos e mantenham-se motivados em ir para a escola. Como podemos perceber na discussão a seguir:

\footnotetext{
E2 - [...] representa a amizade, porque aqui dentro todos têm amigos, são eles que muitas vezes fazem a gente não desistir de vir, eu vim na escola para ver meus amigos, nem vinha mais pelo conteúdo... eu já estava rodado ano passado, mas ele me passaram. Eu nem vinha mais pelos estudos mas sim pelos amigos, e isso não ocorre só comigo mas com um monte de gente, eu penso vou lá na escola para ver meus amigos e quem sabe eu resolva meus problemas.

E3 - Ou você vem desanimado pra escola e chega um colega e muda totalmente teu ânimo... não existe coisa melhor que isso!

E2 - Você esquece os problemas.

E6 - Eu entendo que é uma etapa da vida, mas que eu vou guardar pro resto da vida. (Dados do registro de campo, 23/06/2016)
}

Para Dayrell (2007) é essa sociabilidade entre os jovens, que faz com que muitas vezes, eles apropriem-se da escola, elaborando e produzindo novos sentidos para esse espaço: "Os grupos se constituem como um espaço de trocas subjetivas, mas também palco de competições e conflitos" (DAYRELL, 2007, p. 1121). Para os estudantes as relações que estabelecem entre si são mais relevantes do que as regras e normas escolares: "[...] constituindo-se em uma referência determinante na construção de cada um como aluno, tanto para adesão quanto para a negação desse estatuto" (DAYRELL, 2007, p. 1121).

Vale destacar que os jovens passam uma parte significativa de sua vida no espaço da escola e ali, para além de aprender a ler, estudar, produzir conhecimentos, também se encontram e criam, neste tempo presente, outros modos de se relacionar 
e de se apoiar uns aos outros, em uma relação horizontal que também, segundo apresentam suas imagens, deveriam ser valorizados pela instituição escolar.

\section{CONSIDERAÇÕES FINAIS}

Ao final deste artigo, destacamos o desejo e a motivação dos estudantes em participar da pesquisa, mediante a produção e discussão de imagens, tendo suas vozes e olhares valorizados nesta investigação - tal como gostariam que acontecesse na escola. A metodologia da pesquisa por meio de grupos focais, alinha-se com a proposta de assegurar aos jovens um espaço de autorização e legitimidade de fala e escuta, ressaltando seus olhares e suas vozes. Juntamente à técnica de foto elicitação, permitiu, também, que eles pensassem sobre seu lugar de estudantes e suas possibilidades de criação neste ambiente.

Entendemos, por meio da investigação, que os jovens têm o desejo de falar, questionar e pensar sobre a escola, sobre seus processos de ensino e de aprendizagem - movimento o qual não imaginávamos encontrar com tanto interesse ao iniciar a pesquisa. Eles referem a necessidade de escuta por todos aqueles que compõem o cenário escolar: professores, gestores, pais - inclusive, os próprios colegas. Solicitam que a escola deveria promover mais espaços que possibilitem o diálogo, a discussão e a troca de ideias.

Entre estes espaços, apontam os encontros entre colegas como fundamentais para a função social da escola: grande parte dos estudantes participantes da investigação ressalta a importância das relações interpessoais, por meio da amizade entre os jovens e entendem que é na escola que tais relações deveriam ser incentivadas. Especialmente, nos momentos que antecipam a saída da escola, como é o caso dos estudantes concluintes do Ensino Médio. Questionamo-nos sobre suas possibilidades futuras, sobre a ênfase que (não apenas) a escola faz recair sobre eles e igualmente se veem entrelaçados a este "chamado", ao fotografar as escadas e as saídas como alguns dos elementos que marcam esta despedida.

A partir dos grupos focais e da foto elicitação foi possível compreender os múltiplos papeis desempenhados pela escola na vida dos estudantes concluintes de Ensino Médio. Funções que perpassam o aspecto político, pedagógico e disciplinar 
da instituição escolar, mas igualmente sua tarefa de colocar em relação todos os participantes que convivem neste espaço produtor de vidas.

Os participantes da pesquisa destacam também a necessidade de serem reconhecidos como sujeitos de seu processo de aprendizagem, ressaltando o quanto entendem acerca do universo escolar, de suas regras, seus limites, suas contradições, suas possibilidades. Não deixam de apontar as contradições e as denúncias de um ensino ainda pautado por um referencial tradicional, que dificulta um processo de aprendizagem mais livre - que talvez não precisasse "correr com o conteúdo", se preocupando com os processos de ensino e de aprendizagem dos estudantes. Contudo, os participantes também indicam que há possibilidades de produzir outros modos de ensinar e de aprender, apostando que ao "subir os degraus do conhecimento" eles possam encontrar "novos começos" que levem em conta o protagonismo jovem e a vida juvenil que pulsa na escola.

\section{REFERÊNCIAS}

AQUINO, Júlio G. Do cotidiano escolar: ensaios sobre a ética e os seus avessos. São Paulo: Summus, 2000.

BANKS, Marcus. Dados visuais para pesquisa qualitativa. Tradução de José Fonseca. Porto Alegre: Artmed, 2009.

Visual methods in social research. London: Sage, 2001.

BRAZÃO, Paulo. O diário do diário etnográfico electrónico. In: SOUSA, J.; FINO, C. (orgs). A escola sob suspeita. Porto: Asa Editores, 2007. p. 289-307.

DAYRELL, Juarez. O jovem como sujeito social. Revista Brasileira de Educação, Rio de Janeiro, set-dez. 2003, v. 24, n. 24, p. 40-52. Disponível em:

http://www.scielo.br/pdf/rbedu/n24/n24a04.pdf. Último acesso: 08 mai 2021.

DAYRELL, Juarez. A escola "faz" as juventudes? Reflexões em torno da socialização juvenil. Educação e Sociedade, Campinas, out. 2007, v. 28, n. 100, p. 1105-1128. Disponível em: http://www.scielo.br/pdf/es/v28n100/a2228100.pdf. Último acesso: 08 mai 2021.

FOUCAULT, Michel. Microfísica do poder. Rio de Janeiro: Paz e Terra, 2015.

A Arqueologia do Saber. Rio de Janeiro: Forense Universitária, 2002.

FOUCAULT, Michel. Vigiar e punir: nascimento da prisão. Petrópolis: Vozes, 1997. 
GATTI, Bernadete. Grupo focal na pesquisa em ciências sociais e humanas. Brasília: Liber Livro, 2005.

LEÃO, Geraldo; DAYRELL, Juarez Tarcísio; REIS, Juliana Batista dos. Juventude, projetos de vida e Ensino Médio. Educação e Sociedade, Campinas, out-dez. 2011, v. 32, n. 117, p. 1067-1084. Disponível em:

http://www.scielo.br/pdf/es/v32n117/v32n117a10.pdf. Acesso em: 08 mai. 2021.

LEITE, Fernanda Moreira; PESSOA, Manuella Castelo Branco Pessoa; SANTOS, Denise Pereira dos Santos; ROCHA, Gabriela Fernanda; ALBERTO, Maria de Fatima Pereira. O sentido da escola: concepções de estudantes adolescentes.

Revista da Associação Brasileira de Psicologia Escolar e Educacional, v. 1, n. 1, p. 339-347, 1996.

Disponível em: https://abrapee.files.wordpress.com/2016/09/abrapee v20n2.pdf . Último acesso: 08 mai. 2021.

LOPES, Maura Corcini; VEIGA-NETO, Alfredo. Os meninos. Educação \& Realidade, Porto Alegre (RS), v. 29, n.1, p. 229-239, jan./jun. 2004.

MASSCHELEIN, Jan; SIMONS, Maarten. Em defesa da escola. Belo Horizonte: Autêntica Editora, 2014.

SCHWERTNER, Suzana Feldens; CONRAD, Jaqueline Maria. Um click na escola: olhares e discursos de jovens estudantes sobre a instituição escolar contemporânea. Caderno Pedagógico, Lajeado, v. 13, n. 2, p. 28-46, 2016. Disponível em: < http://www.univates.br/revistas/index.php/cadped/article/view/1126 >. Acesso em: 08 mai. 2021.

SCHWERTNER, Suzana Feldens; FISCHER, Rosa Maria Bueno. Juventudes, conectividades múltiplas e novas temporalidades. Educação em Revista: Belo Horizonte. v. 28, n. 1, p. 395 - 420, mar. 2012. Disponível em: < https://www.scielo.br/scielo.php?pid=S0102-

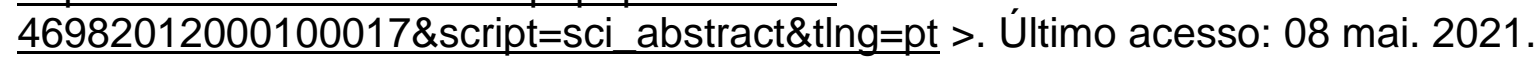

SCHWERTNER, Suzana Feldens. Palavras e imagens sobre amizade jovem na contemporaneidade. Educação \& Realidade, vol. 37, no 01, p. 163-185, 2012. Disponível em: < https://seer.ufrgs.br/educacaoerealidade/article/viewFile/13947/16038 >. Último acesso: 08 mai. 2021.

SIBILIA, Paula. Redes ou paredes: a escola em tempos de dispersão. Rio de Janeiro: Contraponto, 2012. 